\title{
A regra do jogo: rupturas e continuidades na regulação dos meios em tempos de convergência digital
} Gislene Moreira Gomes

\section{Resumo}

0 fenômeno da convergência digital tem provocado novas lógicas de acomodação tecnológica e normativa dos setores do audiovisual, telecomunicações e informática. Mas essas novidades significam alterações nas regras dos jogos de poder destes segmentos? Este trabalho reivindica o papel da História no debate das reacomodações dos marcos regulatórios contemporâneos, reconstituindo os padrões de acomodação e conflito nas Políticas de Comunicação na Argentina, no Brasil e na Venezuela. 0 estudo sistematiza as etapas normativas do primeiro século de estruturação da radiodifusão na tentativa de compreender os processos de mudanças nas leis de comunicação no novo milênio.

\section{Palavras-Chave}

Convergência digital. Regulação midiática. América Latina.
Gislene Moreira Gomes I ggomes@uneb.br Professora Doutora na Universidade do Estado da Bahia - Brasil, onde coordena o Curso de Comunicação Social da Chapada Diamantina.

\section{Introdução}

As mídias digitais parecem fazer convergir as mais distintas correntes teóricas e escolas da comunicação sobre as novidades inauguradas pelo fenômeno da convergência tecnológica. Desde a crítica Economia Política (Bolaño e Brittos, 2009) passando pelos marcos dos estudos antropológicos (Jenkis, 2008), da publicidade (Austin e Aitchison, 2007), aos que tradicionalmente celebram os avanços da tecné (Lévy, 2004), todos afirmam que mudanças profundas estão ocorrendo nas lógicas de produção, transmissão, recepção e normatização dos setores da informática, audiovisual e telecomunicações.

Em termos tecnológicos, o fenômeno significa que as tecnologias e os serviços logísticos das telecomunicações, como transmissão de dados via satélite, cabos de conexão à internet e telefonia, sejam transmutados em redes potenciais de distribuição de conteúdos infocomunicacionais, anteriormente restritos à radiodifusão, como sinais de televisão e rádio. 
Economicamente, essas mudanças estão impactando na organização de setores historicamente distintos, como a radiodifusão, as telecomunicações e a informática, provocando novos modelos de exploração, regulação e gestão. 0 fenômeno tem provocado novas dinâmicas produtivas, como fusões, concentração e hegemonia de grandes conglomerados informacionais globais (Brittos, 2009; Bolaño, 2005; Matrini e Becerra, 2009; McQuail, 2005).

No que se refere às lógicas de acomodação expressas nos marcos normativos, é interessante destacar que os três setores se fixaram historicamente sobre marcos distintos, os quais agora tendem a fundir-se em novos modelos regulatórios (McChesney, 2005). A União Europeia, por exemplo, tem inaugurado regras que fundem a normatização dos serviços de telecomunicações e audiovisuais em leis mistas. Nos últimos cinco anos, só a Espanha decretou três novas leis ${ }^{1}$ que reformularam toda a sua estrutura regulamentária junto aos segmentos envolvidos na convergência digital.

Mas na América Latina, o que realmente há de novo na regulação midiática? 0 avanço das mídias digitais permite alterar as regras do jogo? Este estudo se concentra sobre este cenário complexo e em mutação, procurando os sinais de respostas no passado. Baseado em uma abordagem metodológica histórico-estrutural ${ }^{2}, 0$ trabalho analisa a trajetória dos jogos de poder envolvidos na constituição dos marcos normativos da radiodifusão e das telecomunicações, duas áreas estratégicas da convergência digital, para compreender as inovações regulatórias e as transformações nas dinâmicas de acomodação e conflito de interesses deste novo momento histórico.

A análise comparativa de Argentina, Brasil e Venezuela, três dos mais importantes mercados de comunicação do continente, busca construir um panorama do primeiro século da estruturação da radiodifusão, entendendo que ela funciona como espelho das demais políticas da comunicação, e visto que os campos da informática e das telecomunicações só adquiriram maior relevância normativa desde 0 final do século XX.

Os dados foram coletados a partir de uma revisão bibliográfica, em geral dispersa e fragmentada, compreendendo o conceito de leis de meios de comunicação como processo histórico, resultado de lutas e dinâmicas de poder. A regulação midiática, seja em tempos de convergência ou não, é parte de um processo de estruturação no qual atores historicamente posicionados

Lei 7/2010, novo marco Geral da Comunicação Audiovisual, Lei 3/2013, que instaurou a Comissão Nacional dos Mercados e da Competência como árbitro na área e criou a mestiça Direção das Telecomunicações e do Audiovisual para políticas na área, e a Lei 9/2014, que revisou a regulação das Telecomunicações.

Sanchéz Ruiz (1991) desenvolveu um método de pesquisa multidimensional que mescla dimensões econômicas, políticas, históricas e culturais para os estudos de mudança social. Neste artigo, é feita uma adaptação deste modelo, com ênfase no tema da História, ainda que considerando as outras esferas, para entender o jogo das regulações. 
confrontam seus projetos políticos e usam

recursos disponíveis para manter ou mudar regras e estruturas (Moreira, 2011).

Os relatos de outrora servem como ponto de partida para interpretar os processos de mudanças nas leis de comunicação no século XXI. Por trás das semelhanças das normas anteriores, se acredita que estão escondidas as marcas de processos distintos que podem auxiliar a entender os diferentes caminhos e modelos que estão sendo desenvolvidos na contemporaneidade.

\section{A indefinição normativa nos princípios do século XX}

Quando do nascimento dos primeiros meios eletrônicos, como o rádio, 0 mundo vivia entre duas guerras mundiais, 0 auge da maior crise econômica do capitalismo norte-americano e a explosão do comunismo e ascensão do nazismo. Este contexto turbulento e indefinido marcou a emergência do uso massivo da comunicação e das primeiras práticas regulatórias das mídias de massa.

No panorama mundial, as práticas de regulação da inovadora radiodifusão refletiram a experimentação de modelos de exploração. Oscilava-se entre a centralidade e controle estatal direto em práticas totalitárias, como a do Ministério das Comunicações e Propaganda Nazista, e a ação privada provocada pela indústria cultural estadunidense. Depois da guerra, na Europa Ocidental prevaleceram os "sistemas públicos de comunicação", com privilégio da função de propaganda e intervenção estatal. Nos regimes de inspiração soviética, o controle estatal único assumiu a direção; e 0 imperialismo mercantil dos EUA disseminou o modelo de exploração comercial com ação regulatória reduzida (Bustamante, 2005).

Parece importante destacar que o desenho norte-americano se definiu ao final dos anos 30 , quando o Communications Act 34 criou a Federal Communications Commission (FCC), o primeiro espaço político regulatório dotado de relativa autonomia institucional ${ }^{3}$. Esta medida firmou a opção norte-americana por uma ação estatal reduzida e conformou o modo mercantil privado como referência mundial (McChesney, 1995).

Na América Latina, nos primeiros anos, 0 modelo era ainda indefinido. As legislações eram inexistentes ou fragilizadas, e os cenários de grandes instabilidades políticas globais justificavam a eliminação gradual dos opositores e acercaram os governos de agentes midiáticos "confiáveis". 0 grande destaque deste momento inicial foi a rapidez com que os governos locais se definiram pelo modelo de exploração privada. 
No Brasil, o desenho inicial foi previsto pelo Decreto $\mathrm{n}^{0} 16.657$, de 1924, o qual estabelecia um sistema radiofônico sem finalidade de lucro e educativo-cultural operado por uma elite intelectual, apoiada pelo controle estatal (Ramos e Santos, 2007). Na Argentina, sucessivos decretos (Decretos de 1922, 1924, 1925, 1928 e a I Lei do Broadcasting de 1929) ordenaram 0 setor e garantiram uma legislação mais próxima do modelo norte-americano, privilegiando a exploração mercantil (Mastrini, 2009). Na Venezuela, a proteção do Estado ditatorial de Juan Vicente Gómez (1908-1935) ao novo negócio dispensou a necessidade de regras formais e a fixação de leis específicas (Aguirre, 2005).

Já no final dos anos 1930, estes desenhos estavam definidos. Em geral, os países experimentaram pouco, e optaram pela exploração privada em um período muito curto, e a discussão do modelo foi quase ausente (com exceção da Argentina em um breve debate em 1938, que será explicitado mais adiante), e 0 desenho mercantil acabou prevalecendo "naturalmente".

\section{A definição regulatória conservadora}

A passagem do momento indefinido para marcos normativos mais estáveis aconteceu à medida que o negócio privado amadurecia, provocado principalmente pelo advento da televisão. 0 novo meio despertou maiores possibilidades econômicas e de controle estatal, e aumentou os interesses e as tensões em torno da regulação da radiodifusão no continente.

Os EUA se converteram em um aliado poderoso da comunicação massiva latino-americana e interferiram diretamente na constituição normativa regional ${ }^{4}$ (Gumucio e Tufte, 2005). Com forte influência econômico-tecnológica, os EUA financiaram os produtos e modelos técnicos e estéticos de exploração mercantil. Por outro lado, em aliança com as elites locais, apoiou as ditaduras que eliminaram os antagonismos e sustentaram marcos normativos contraditórios, os quais permitiram liberdade de exploração mercantil com controle estatal autoritário. Essa combinação inusitada possibilitou a estruturação da Indústria Cultural e sua proclamada liberdade de expressão, em paralelo à eliminação das vozes dissidentes em longos períodos de acomodação de interesses antitéticos.

Na Argentina, no entanto, esse foi um período repleto de tensões e rupturas. 0 golpe de Estado que instalou a ditadura de Uriburu (1930-1938) implantou o Decreto n ${ }^{0}$ 21.004/33, o qual estabeleceu a censura prévia e as restrições legais e técnicas que favoreceram a concentração mercantil por mais de 20 anos. 0 primeiro (1946-1952) e 0 segundo 
(1952-1955) governos de Perón foram marcados por tentativas de alterar este cenário, através de várias medidas de estatização das comunicações. Contudo, essas iniciativas foram barradas por outro golpe de Estado, que estabeleceu a Nova Lei de Radiodifusão de 1957 para garantir a propriedade dos meios aos aliados conservadores.

Depois do exílio, Perón retornou a um terceiro mandato (1973-1974) disposto a enfrentar o tema dos meios, despertando a mais raivosa reação dos empresários midiáticos e militares conservadores. A ditadura argentina (1976-1983) apoiava economicamente o novo negócio. De outro, se encarregava da eliminação dos opositores políticos e concorrentes econômicos por meio de torturas, proscrição política, assassinatos e desaparecimentos. Esse vínculo entre mídia e ditadura foi uma marca evidente da estruturação autoritária da radiodifusão argentina, que consolidou o grupo Clarín (Mastrini, 2009).

No Brasil, essa relação foi mais sutil. 0 país forjou sua principal legislação setorial, o Código Brasileiro de Telecomunicações (CBT), em 1962. Este marco foi gerado em um legítimo, ainda que frágil, período de democracia, o que favoreceu a legitimidade pública do marco. Tanto que em 2015 ele ainda é a principal referência normativa para a radiodifusão no país. A fase de regulação privado-autoritária brasileira se iniciou na primeira gestão de Getúlio Vargas, e foi intensificada no curto período democrático dos anos 50/60, que instaurou o Código Brasileiro de Telecomunicações de 1962, que, entre outras medidas, criminalizava a exploração irregular das rádios comunitárias ilegais (Ramos e Santos, 2007).

Um dos raros momentos de tensão na acomodação normativa brasileira foi o veto de João Goulart ao CBT, em 1962, o qual foi derrubado pelo Congresso. A resposta empresarial foi a consolidação da aliança entre as elites midiáticas e os militares conservadores. Essa união foi determinante para a consolidação do grupo Globo, um dos maiores gigantes do continente, e fundamental para a legitimidade do regime ditatorial por mais de 20 anos (Brittos e Bolaño, 2005). Em termos de alianças históricas entre elites políticas e meios massivos, o caso brasileiro é 0 que mais exibe padrões de regularidade, continuidade e amadurecimento das alianças entre 0 Estado e 0 capital midiático.

Na Venezuela, estas alianças deram sinais desde 0 princípio, nos anos 1920. Desde o seu nascimento, a aliança entre meios privados e ditadura garantia que os grupos comunicativos contrários "à ordem pública" fossem criminalizados, e as ideologias comunistas e anarquistas, assim como partidos e sindicatos fossem proscritos. Depois de estabilizada a situação política, a instauração da democracia do Ponto Fixo ${ }^{5}$ na 
Venezuela, em 1940, foi acompanhada de uma série de decretos e disposições normativas desarticuladas e complementares à lei de 1940. Até os anos 1990, essas alterações não significaram nenhuma mudança significativa no modelo de radiodifusão. Esta ausência regulamentária ou silêncio normativo refletia 0 acordo tácito entre elites políticas e empresários que permitiu a concentração midiática. Foi neste período que se estabeleceu o grupo Cisneros, outro gigante da radiodifusão no continente (Aguirre, 2005).

Em comum entre os três países analisados, parece imperativo destacar que 0 grande ator responsável pela consolidação das normas midiáticas foram as Forças Armadas e seus mecanismos de controle e repressão. Também é importante ressaltar o papel dos militares e de seus governos autoritários na fixação das primeiras leis de telecomunicações como assunto de segurança nacional. Financiados pelo governo norte-americano, eles foram responsáveis também pela instalação dos caríssimos parques tecnológicos de distribuição dos primeiros serviços de telefonia.

\section{A homogeneização neoliberal}

Os anos 1990 foram marcados pela chegada da internet e pelos primeiros sinais de interferência do mundo globalizado na definição das regras do jogo da regulação normativa dos meios latino- americanos. Quando a relação entre os projetos da iniciativa privada e os interesses das elites políticas parecia haver se estabilizado, surgiram as dinâmicas de privatização neoliberal ${ }^{6}$. Esta etapa representou a ação massiva do capital na área cultural e a substituição da função controladora do Estado. Do ponto de vista econômico, significou a eliminação das restrições regulatórias à concentração da propriedade dos meios, e do político, foi a apropriação corporativa do espaço público (Murdock, 2005).

Nesta etapa, a diversidade de modelos de exploração, os questionamentos ao sistema privado e as tentativas de comunicação pública foram engolidos pela avalanche homogeneizadora que consolidou a mercantilização comunicacional. Outra característica importante foram as privatizações aceleradas dos altos investimentos em infraestrutura de telecomunicações, as quais foram asseguradas com recursos públicos no período da consolidação autoritária das indústrias da radiodifusão (Bolaños, 2007).

A partir do aumento da influência da informática e das redes de transmissão, a histórica distinção entre as políticas de radiodifusão e de telecomunicações passou a ter mais pontos de encontro tecnológicos e negociais, aproximando também os modelos de regulações dos dois setores (Cuilenburg e McQuail, 2005). 
A globalização, além de avanços tecnológicos

digitais, trouxe ainda a interferência direta

do capital estrangeiro, e das inovações

tecnológicas digitais, novas dinâmicas de

concorrência, endividamentos às indústrias

familiares nacionais, fusões, e a hegemonia dos

grandes conglomerados regionais. Tudo isso, em

menos de duas décadas.

Primeiramente, as políticas neoliberais

se dedicaram a privatizações separadas

dos negócios da radiodifusão e das

telecomunicações, e prevaleceram as medidas

de abertura ao capital internacional apenas

no setor das teles. Mas, com a continuidade

e 0 avanço da convergência digital, tem se

conformado um novo momento no qual as

interferências entre os dois setores começaram

a alterar as dinâmicas de poder na regulação da

radiodifusão. E ainda no final dos anos 2000 ,

iniciam-se as tentativas de normatizar ainda

0 mercado da internet.

Nos países em análise, é interessante identificar que, até o final da década de 1990, a única grande novidade foi a inserção de atores internacionais, em especial as empresas de telefonia no mercado, que pressionaram as privatizações e as normas telecomunicativas neoliberais.

No Brasil, a principal regulação neoliberal foi aprovada no governo de Fernando Henrique Cardoso (1994-2002) e refletiu a força das empresas familiares de radiodifusão. A Lei
Geral de Telecomunicações $n^{0}$ 9.472/97 garantiu

as privatizações da telefonia, mas deixou

inalterado 0 setor da radiodifusão, que continua operando com o CBT de 1962. Esta disputa de interesses entre radiodifusores e as empresas de telefonia ainda está indefinida, e se, por um lado, o Estado parece se omitir da arbitragem, o capital já dá sinais de esquemas de fusões e alianças negociais que favorecem mecanismos de concentração e acomodação de interesses.

É interessante enfatizar que, no caso brasileiro, nem a redemocratização, nem a virada à esquerda nas gestões petistas de Lula (2002-2008) e Dilma (2009-2014) foram suficientes para alterar as regras do jogo. Apesar das várias tentativas destes governos, como a realização da I Conferência de Comunicação (2009), a nova esquerda brasileira foi incapaz de promover mudanças na regulação midiática. A principal iniciativa normativa do período é o Marco Legal da Internet (Lei $\left.\mathrm{n}^{0} 12.965 / 2014\right)$, o qual se fixa mais sobre os usos e crimes no ambiente virtual do que na regulamentação do negócio.

Na Argentina, essa lógica de privatizações das telecomunicações foi estabelecida de maneira precoce a partir de sucessivos decretos que alteraram a Lei $n^{0}$ 22.285/80 durante as décadas de 1980 e 1990. Em 2005, a gestão de Néstor Kirchner favoreceu a concentração de licenças dos radiodifusores, barrando 0 avanço das teles. Já no governo de Cristina Kirchner, o 
país aprovou a polêmica Lei de Serviços de Comunicação Audiovisuais (Lei nº 22.285/09).

A inovadora medida argentina, por um lado, enfrentou radicalmente 0 tema da concentração midiática de grupos como Clarín, instituiu a cota de $33 \%$ de exploração pública e não estatal da radiodifusão, e iniciou um dos maiores debates sobre os direitos de propriedade comunicacional, o qual ainda paralisa a nova legislação em um infindável processo de judicialização. Por outro, silenciou sobre 0 assunto da exploração da telefonia, redes de transmissão e internet, indicando que a convergência digital ainda será um tema a ser enfrentado posteriormente (Moreira, 2011).

Na Venezuela, a privatização se estabeleceu primeiro com medidas secundárias, como 0 Regulamento de Radiodifusão Sonora e Televisiva 4.530, de 1993. 0 início do governo de Hugo Chávez (1998) também não significou alteração na onda neoliberal das telecomunicações, aprovando, em 2000, a Lei Orgânica de Telecomunicações (LOT/ 36955), que favoreceu a privatização e a exploração mercantil das teles. Só a partir da tentativa de golpe ao seu primeiro mandato (2002) e do acirramento dos conflitos internos foi que a República Bolivariana iniciou as alterações normativas e políticas no cenário midiático venezuelano. As Leis de Responsabilidade Social de Rádio e Televisão, conhecida como Lei Resorte de 2007, impactaram na gestão dos meios eletrônicos, e, mais recentemente, a Nova
Lei de Telecomunicações de 2010, reformou as anteriores e limitou a participação do capital estrangeiro na exploração das telecomunicações e da radiodifusão, além de interferir diretamente na produção de conteúdo de internet, tornando o negócio como de interesse público, passível da intervenção estatal direta.

Diante de todo este cenário exposto, a questão é que as "novas esquerdas" latino-americanas de Hugo Chávez (1998), Lula (2002) e Néstor (2003) e Cristina Kirchner (2007) enfrentaram 0 tema da regulação da radiodifusão de maneira muito distinta. No Brasil, não houve alterações no modelo de exploração, nem nos marcos normativos. Na Argentina, 0 câmbio regulamentário não interferiu nas telecomunicações. E na Venezuela, a resposta tendeu a um retorno à estatização, e não à normatização institucional democrática. Pressionados pelas antigas lógicas, mesmo esses governos iniciaram sua relação no setor seguindo a onda de privatizações, homogeneização e concentração da produção e distribuição dos conteúdos por grandes conglomerados regionais (Mastrini e Becerra, 2006).

No entanto, a experiência venezuelana e 0 polêmico debate do caso argentino indicaram que, em contextos políticos mais tensos, esses governos ousaram inovar nas lógicas de acomodação. Mas será que apontam a superação da tradição do controle estatal ou da exclusiva apropriação mercantil para 0 
estabelecimento de uma comunicação mais voltada ao interesse público? 0 momento tende a ser de crise, e entender os episódios críticos dessa longa trajetória regulamentária pode ajudar a elucidar as possibilidades contemporâneas de mudança.

\section{Os episódios críticos e as tentativas de incorporação subalterna}

A ruptura venezuelana remete aos múltiplos episódios críticos que interromperam a sequência, aparentemente tranquila, da estruturação mediática no continente. No entanto, resgatar esses cenários de crise anteriores é um desafio, pois eles não aconteceram de forma linear a nenhum

ciclo político e tiveram contornos muito diferenciados, assim como reivindicações e atores mutantes ${ }^{7}$. 0s episódios críticos não necessariamente significaram inovações normativas, ou alterações do modelo, mas possibilitaram a emergência de pautas, atores e demandas distintos à referência mercantil. Em sua maioria, esses episódios se cruzaram com os momentos de avanço do modelo privado.

A seguir, são apresentados os momentos críticos nos países observados. Neste ponto, as diferenças são muito maiores e mais explícitas. 0s casos se diferenciaram na quantidade e intensidade dos episódios em cada país, além de

Quadro 1: Quadro dos episódios críticos de integração

\begin{tabular}{|c|c|c|c|}
\hline $\begin{array}{l}\text { Episódios críticos } \\
\text { de integração }\end{array}$ & Argentina & Brasil & Venezuela \\
\hline $\begin{array}{l}\text { Momentos mais } \\
\text { significativos }\end{array}$ & $\begin{array}{l}\text { Comissão de Estudo e } \\
\text { Reorganização dos Serviços } \\
\text { de Radiodifusão (1938) } \\
\text { Lei de Radiodifusão 14.241/53 } \\
\text { e Estatuto do Jornalista de } 1953 \\
\text { Decretos de estatização do setor } \\
\text { de } 1973 \text { e } 1974 \\
\text { Projeto Cocode de } 1986 .\end{array}$ & $\begin{array}{l}\text { Decretos de } 1961 \\
52 \text { vetos de Jango ao CBT/62 } \\
\text { Constituinte e o Capítulo } 5 \\
\text { da Constituição de } 1988 \\
\text { Lei do Cabo 8.977/95 } \\
\text { Lei de Radiodifusão } \\
\text { Comunitária (9.612/98) }\end{array}$ & $\begin{array}{l}\text { Projeto Ratelve 1975/76 } \\
\text { Comitê por uma Rádio-televisão } \\
\text { de Serviço Público (1993) }\end{array}$ \\
\hline Similitudes & \multicolumn{3}{|c|}{$\begin{array}{l}\text { São polêmicas; ativaram reações conservadoras, e não foram } \\
\text { experiências que se consolidaram como modelos alternativos. }\end{array}$} \\
\hline Diferenças & $\begin{array}{l}\text { Mais frequentes e intensas; amplo } \\
\text { repertório de demandas e atores; } \\
\text { única aliança estatal experimental. }\end{array}$ & $\begin{array}{l}\text { Mais esporádicas e tensas. } \\
\text { Sucessos relativos só depois } \\
\text { da redemocratização; lutas } \\
\text { mais institucionalizadas. }\end{array}$ & $\begin{array}{l}\text { Casos muito isolados, } \\
\text { experimentados na democracia } \\
\text { elitista; vinculados a } \\
\text { intelectuais e sem relação com } \\
\text { as massas; nunca significaram } \\
\text { mudanças efetivas. }\end{array}$ \\
\hline
\end{tabular}


variar na forma de solucionarmos, no conteúdo dos embates e nos atores envolvidos. Mas todos se assemelham outra vez quando o tema é o desfecho dramático que todos esses eventos tiveram.

Nesta breve sistematização, a Argentina se destaca, pois é o único país que entra nos episódios de integração já nos anos 1930, com uma discussão surgida ao final da ditadura de Uriburu. Também porque, depois, incorpora a luta da categoria dos trabalhadores de meios. 0 Estatuto do Jornalista, aprovado por Perón, em 1953, reflete um acúmulo organizativo diferente do reconhecimento profissional em outros países, como Brasil ou Venezuela. Nesses casos, o Estado privilegiou instrumentos dirigidos à cooptação dos novos trabalhadores, convertendo-os em trabalhadores privilegiados, com contatos e vínculos com as elites. Por isso, suas histórias de reconhecimento profissional não aparecem no quadro de episódios críticos.

A Argentina peronista foi a única a refletir uma organização de classe dos profissionais da comunicação com uma tradição mais vinculada a outras lutas sindicais. Esses grupos estiveram diretamente envolvidos nas rupturas seguintes, as quais se expressam em uma nova lei de radiodifusão, que, progressivamente, estatizou o setor, rompendo a tradicional aliança com os meios privados, e permitiu possibilidades de autogestão e negociação da classe mediática proletária com o Estado populista.
Na reabertura democrática, até o início dos anos 2000, a única ação que traduzia as tentativas de incorporação das demandas subalternas ocorreu no processo de redemocratização e ficou conhecida como Projeto Cocode, mas não teve nenhuma tradução em mudanças normativas.

0 quadro também evidencia que os debates foram mais frequentes na Argentina, e esses momentos afetaram a organização do segmento, romperam os acordos Estado-Mercado, alteraram as estruturas, e ampliaram as demandas, formando um movimento de luta pela comunicação com perspectivas mais ousadas. As conquistas temporárias da época peronista foram sufocadas e reprimidas pelo golpe ditatorial nos anos 1970, mas a experiência marca a organização precoce de um movimento com conquistas concretas, e aprendizagens políticas práticas.

No Brasil, o debate público foi quase ausente da agenda, e até os anos 1960 foram insignificantes. No curto período democrático dos anos 1950/60, foram realizadas algumas tentativas, porém provocadas pela própria Indústria Cultural, que buscava uma regulação específica. 0 momento de tensão foi feito desde o Estado, nas presidências de Jânio Quadros e João Goulart, quando estes pressionaram os empresários. 0 debate mais significativo foram os vetos de Jango ao CBT, em 1962, os quais despertaram a reação das elites políticas e comunicativas que culminaram com o golpe de 1964. 
No debate da Constituinte de 1988, fixou-se o capítulo mais paradigmático das tensões na regulação brasileira por conta da batalha partidária pela aprovação do Capítulo V, que trata da comunicação como direito fundamental. Como parte dos avanços democráticos do país, a iniciativa reconheceu as demandas dos grupos não hegemônicos nos artigos 222 a 224, que tratam, entre outras coisas, do Conselho de Comunicação e dos limites à concentração de propriedade. Entretanto, como parte da influência das elites conservadoras, esses avanços nunca foram regulados. Outros debates significativos aconteceram nos anos 1990, como a discussão da Lei do Cabo e a Lei de Radiodifusão Comunitária, com algumas conquistas normativas. No entanto, é importante relembrar que esses avanços só foram possíveis depois da eliminação dos antagonismos mais profundos e tenderam mais a frear a organização subalterna do que a refletir normativas realmente progressistas.

Na Venezuela, a opção das classes médias e dos intelectuais que lutavam pela comunicação pública nas vias institucionais os separou cada vez mais das demandas e estratégias dos movimentos de base. Percebendo a falência das possibilidades de mudanças concretas na regulação de meios na democracia do Ponto Fixo, os grupos de comunicação popular seguiram caminhos paralelos à incidência institucional e construíram apostas mais radicais, conhecidas como guerrilhas comunicativas.
Voltando a uma análise comum a todos esses cenários, outra observação importante é que os embates contra a hegemonia do modelo privado foram mais intensos nos momentos de alternância política. Contudo, o alerta histórico é que as experiências políticas geradas nesses processos muito raramente significaram uma visão da comunicação para além da propaganda instrumental. É conveniente lembrar que as políticas de comunicação implantadas nas gestões de esquerda, como em Cuba, com Fidel (1976-2008), ou no Peru, do Governo de Velasco (1968-1975), ou no Chile, de Salvador Allende (1970-1973), não significaram a construção de modelos de comunicação pública para além do estatal. Prevaleceram nestes governos, nos partidos e sindicatos as políticas de comunicação centralizadas, instrumentais e monopólicas (estatais), muitas delas ainda mais rígidas e unidimensionais do que no modelo privado. 0s modelos plurais e democráticos de comunicação pública parecem sofrer de uma ausência histórica e de orfandade política, sendo uma agenda pendente nos programas da direita e da esquerda.

0 que todas essas experiências e lutas normativas evidenciam é que as discussões por modelos comunicativos tiveram antecedentes históricos. As mobilizações mais contemporâneas sobre 0 tema, como a I Conferência de Comunicação ou o debate em torno do Marco Civil da Internet, tendem a ser apresentadas como inéditas, revelando 
uma desconexão com a memória histórica.

Nestes eventos, parece haver um esquecimento generalizado das antigas discussões e dos resultados obtidos. A diferença do passado está na intensidade, relevância e amplitude da disputa, as quais são condições limitadas aos contextos das épocas em que ocorreram. Mas 0 resgate dessas trajetórias é necessário porque esses eventos representaram aprendizagens importantes, os quais são parte do doloroso processo de construção da hegemonia do modelo privado.

A consolidação das estruturas mercantis concentradas na radiodifusão não ocorreu sem polêmicas, mas as discussões públicas sobre o tema, até o início do século XX, não haviam conquistado nenhuma alteração redistributiva efetiva constante. $\mathrm{E}$ o desenho quase monopólico da estruturação de meios só foi possível com a eliminação das vozes dissidentes.

\section{Fim de ciclo}

Resgatar o processo de conformação das leis de meios permitiu perceber a fixação das perigosas relações de poder, as quais pautaram a construção da legislação setorial desde a emergência da rádio e parece avançar em tempos de convergência entre a maximização dos interesses privados ou o controle estatal.

Nos casos analisados, desenharam-se trajetórias que nos possibilitaram identificar uma tradição regulamentária Latinoamericana, caracterizada pela ausência crescente de políticas estatais de serviço público, deficiência de controles antimonopólios e uma dívida com a democratização dos meios, em especial no que se refere ao reconhecimento dos meios e atores subalternos.

\section{A estruturação dessa tradição obedeceu a} padrões históricos, os quais se organizaram em ciclos. As passagens entre um momento e outro foram permeadas de momentos de tensão e permitiram brechas de integração subalterna, a intensificação de conflitos, e também as reações conservadoras que garantiram a ascendência do modelo mercantil.

Esses períodos parecem constituir um movimento em espiral, em que os desenhos de outros tempos seguem repercutindo nas definições contemporâneas. A releitura histórica da regulação e políticas de meios aponta para uma espiral ascendente de políticas de comunicação, nas quais ciclos continuados e complementários de etapas regulatórias pendulares, em que o controle decisório protagoniza, migravam do Estado autoritário para 0 mercado. Esses movimentos entre a função midiática de publicidade e a da propaganda garantiram e ampliaram a apropriação privada hegemônica da mercadoria audiência. A figura a seguir tenta ilustrar essa trajetória das políticas de comunicação: 


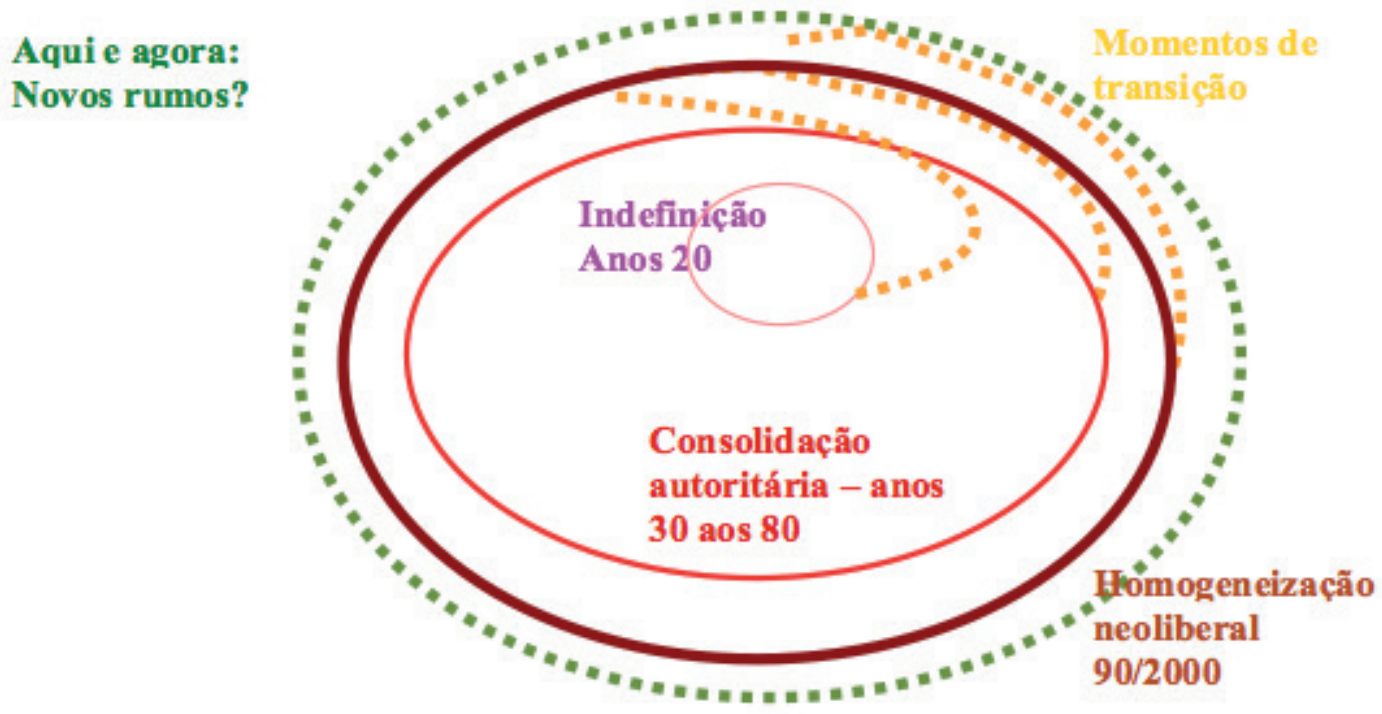

No momento contemporâneo, percebe-se

o início de um ciclo ainda indefinido, que tanto incorpora as reações ao neoliberalismo, plasmadas nos debates e avanços de novas leis de meios, como na Argentina, no Uruguai, na Bolívia, no Equador e na Venezuela, quanto também os elementos de aprofundamento do modelo neoliberal com o fenômeno de convergência digital, expresso na Lei Televisa de México ou na nova Lei de Telecomunicações do Brasil. Estamos assim situados no exato momento da transição para uma nova etapa, na qual 0 velho e o novo se encontram. A definição de qual trajeto irá prevalecer depende dos rumos dos debates contemporâneos.

Da leitura histórica, pode-se constatar que os momentos de passagem e os governos de esquerda são mais favoráveis a debates críticos, o que pode sinalizar para uma opção por modelos alternativos, mas isso não significa, necessariamente, a geração de marcos mais plurais e democráticos, nem a incorporação dos atores subalternos, ou a implementação efetiva e a continuidade histórica das conquistas. 0 que a História nos adverte é a necessidade de processos sociais de mobilização cada vez mais amplos, constantes e duráveis, assim como mecanismos institucionais e amarras políticas que funcionem como blindagem das conquistas contra as possíveis reações conservadoras.

Outra lição importante que a releitura histórica traz é que as trajetórias dos países, mesmo indicando características similares, não foram lineares, nem homogêneas. Essa diferença, em especial 
nos momentos críticos, é chave para entender as distintas formas de ação contemporâneas.

0 mais evidente desse percurso é que, ao fim de quase cem anos legislativos, prevalecem os sinais de continuidade e homogeneidade do modelo privado, em um desenho normativo e distributivo em que poucas vezes (quase nunca) a engenharia de exploração mercantil foi alterada.

Essa situação reflete dinâmicas regulatórias marcadas por larga influência do poder econômico empresarial, e interações de exclusividade entre o poder mercantil e 0 estatal na definição dos interesses pautados nas políticas e regulações midiáticas, vedado às interferências de outros atores.

Esses segmentos superaram seus interesses diferenciados na exploração da mercadoria audiência, para buscar lógicas de acomodação de interesses antitéticos e divergentes. Antes de estabelecer relações de confrontação, conformaram articulações mutuamente benéficas, com um padrão que perpetua negociação favorável aos dois setores (Fox e Waisbord, 2002).

Ao final do milênio, a estruturação da radiodifusão na Argentina, no Brasil e na Venezuela terminou com resultados estruturais similares (conglomerados altamente concentrados), mas com resultados de processo bastante diferenciados. 0s resultados estruturais similares se referem às regras e aos resultados de distribuição do espectro, que eram muito parecidos ao final dos anos 1990. Já nos resultados de processo, destaca-se o acúmulo de aprendizagens, de empoderamento de atores e de construção de um repertório de demandas. Nesse aspecto, é evidente o maior acúmulo argentino em termos de construção de demandas, experiências e conquistas vivenciadas, assim como de organização das lutas. 0 Brasil acumulou resultados mais significativos só depois das reaberturas democráticas, mas lentos e graduais. Na Venezuela, está o cenário mais contraditório, onde se acumularam frustrações e mobilizações não institucionalizadas nos 40 anos da democracia do Ponto Fixo, no movimento mais fragilizado.

Frente ao projeto de aprofundamento do desenho neoliberal, e das reações e alternativas que estão sendo gestadas, me arrisco a pensar que esses desenhos de estruturação são chaves fundamentais para os processos contemporâneos. A América Latina finalizou o século XX com a tendência de construir um novo ciclo no modelo de regulação, o qual está, todavia, indefinido. Porém, a definição dos novos rumos, em grande medida, dialoga com os ciclos anteriores.

Na definição dos rumos do novo ciclo das mídias digitais do século XXI, estão mesclados tanto os resultados da estruturação impressos nas normativas e nas aprendizagens, quanto as novidades trazidas pelas novas correlações de forças construídas em torno dos episódios críticos contemporâneos. Quais serão os novos rumos 
e se eles representarão novas regras no jogo da regulação midiática? Isso só a História irá nos dizer.

\section{Referências}

Aguirre, J. M. (2005). Democratizar la comunicación: El caso Venezuela. aprendiendo de la adversidad.

17 Anuario Ininco - Investigaciones de la Comunicación.

Austin, Mark e Aitchison, Jim (2007). Tem alguém aí? As comunicações no século XXI. São Paulo: Nobel.

Britto García Luis. (2004). Venezuela investigación de unos medios por encima de toda sospecha. Caracas, Fondo Editorial Question.

Brittos e Bolaño (orgs). (2005) Rede Globo: 40 anos de poder e hegemonia. São Paulo: Paulus.

Bolaño, César e Brittos, Valério (2009). Paradigma digital: capitalismo, cultura e esfera pública. Signo y Pensamiento, vol. XXVIII, núm. 54, enero-junio, pp. 82-101. Bogotá: Pontificia Universidad Javeriana.

Bustamante, E. (2005). Políticas de comunicación y cultura: Nuevas necesidades estratégicas. In C. Bolaño, G. Mastrini \& F. Sierra (Eds.), Economía política, comunicación y conocimiento: Una perspectiva para américa latina (). Buenos Aires: La Crujía.

Cuilenburg, \& McQuail, Denis. (2005). Cambios en el paradigma de política de medios. hacia un nuevo paradigma de políticas de comunicación. European Journal of Communication, 18(2), 181-207.

Fox, Elisabeth. 1988. Media Polices in Latin America: an Overview. In Fox, E. (ed.) Media and politics in Latin America: The Struggle for Democracy. London: Sage. 6-35. . (1998). Latin american

broadcasting: From tango to telenovela. Luton, UK: John Libbey Media.

Fox, Elisabeth, \& Waisbord, Silvio. (2002). Latin politics, global media (1st ed.). Austin: University of Texas Press.

Garnham, Nicolas. (1990). Capitalism and communication. London: Sage.

Gumucio-Dagron, A., Tufte, T., \& (coord.). (2006).

Communication for social change: Antology historical and contemporary readings. New Jersey: CFSC Consortium.

Jenkins, Henry (2008). Cultura da Convergência. São Paulo: Aleph.

Mastrini, Guillermo. (org.). (2009). Mucho ruido, pocas leyes: Economía y políticas de comunicación en argentina 1920-2007. Buenos Aires: La Crujía.

Mastrini, Guillermo, \& Becerra, Martín. (2006).

Periodistas y magnates: Estructura y concentración de las industrias culturales en América latina. Buenos Aires, Prometeo.

Moreira, Gislene (2011). Las Hormigas de Macondo: Contrahegemonía y políticas de comunicación comunitaria en Argentina, Brasil y Venezuela. México, Flacso. Tesis de doctorado.

Mosco, Vicente. (1996). The political economy of communication. London: Sage.

Murdock, Gaham. (2005). Continental shifts: capitalism, communications and change in Europe. Revista Comunicacao e Sociedade. Volume 7. N.01. 2005. Disponible en http://revcom.portcom.intercom. org.br/index.php/cs_um/article/view/4704

Plot, Martín y Semán, Ernest. (2007). Mapping

Latin America's response to neoliberalism y neoconservatism. En: Constellations Rewiew. Volume 14, Edición 3, páginas 355-372. Septiembre de 2007. Raboy, Marc y Padovani, Claudia. (2010). Mapping global media polices: Concepts, Frameworks, Methods. In Communication, Culture \& Critique. Edición especial: Media Governance: New Policies for Changing Media Landscape. Volume 3, Issue 2, páginas 150-169, Junio 2010. 
Ramos, M., \& Santos, S. d.. (2007). Políticas de

comunicação: Buscas teóricas e práticas. São Paulo:

Paulus.

Sánchez-Ruiz, Enrique. (1991). Medios de difusión y

sociedad. Centro de Estudio de la Información y de la

Comunicación. Universidad de Guadalajara: México.

Sel, Susan. (. (2010). Políticas de comunicación en el capitalismo contemporáneo - América Latina y sus encrucijadas. Buenos Aires, Clacso. 


\section{The game Rule: ruptures and continuities in the regulation of media in digital convergence}

\section{Abstract}

The phenomenon of digital convergence has created new logical technology accommodations and rules in audiovisual, telecommunications and information technology. But these innovations mean changes in the rules of the power game these sectors? This paper claims the role of history in the discus of contemporary laws, reconstituting the standards of accommodation and conflict in Communication Policies in Argentina, Brazil and Venezuela. The study explores the normative stages of the first century of structuring broadcasting in trying to understand the processes of change in communication laws in the new millennium.

\section{Keywords}

Digital convergence. Media regulation. Latin America.

\section{La regla del juego: rupturas y} continuidades en la regulación de los medios en la convergencia digital

\section{Resumen}

El fenómeno de la convergencia digital ha provocado nuevas lógicas de acomodación tecnológica y normativa del audiovisual, telecomunicaciones e informática. Pero esas novedades significan alteraciones en las reglas de los juegos de poder en estos sectores? Este trabajo invoca el rol de la historia en el debate acerca de las reacomodaciones reglamentarias contemporáneas, reconstituido los patrones de acomodación y conflicto en las Políticas de Comunicación de Argentina, Brasil y Venezuela. El artículo sistematiza las etapas normativas del primer siglo de estructuración de la radiodifusión con el intento de compreender los procesos de cambio en las leyes de comunicación del nuevo milenio.

\section{Palabras clave}

Convergencia digital. Reglamentación mediática. América Latina. 


\section{Expediente}

A revista E-Compós é a publicação científica em formato eletrônico da Associação Nacional dos Programas de Pós-Graduação em Comunicação (Compós). Lançada em 2004, tem como principal finalidade difundir a produção acadêmica de pesquisadores da área de Comunicação, inseridos em instituições do Brasil e do exterior.

\section{E-COMPÓS I www.e-compos.org.br I E-ISSN 1808-2599}

Revista da Associação Nacional dos Programas de Pós-Graduação em Comunicação.

Brasília, v.18, n.3, set./dez. 2015.

A identificação das edições, a partir de 2008, passa a ser volume anual com três números.

Indexada por Latindex I www.latindex.unam.mx

\section{CONSELHO EDITORIAL}

Alexandre Farbiarz, Universidade Federal Fluminense, Brasil Alexandre Rocha da Silva, Universidade Federal do Rio Grande do Sul, Brasil Ana Carolina Damboriarena Escosteguy, Pontifícia Universidade Católica do Rio Grande do Sul, Brasil

Ana Carolina Rocha Pessôa Temer, Universidade Federal de Goiás, Brasil Ana Regina Barros Rego Leal, Universidade Federal do Piauí, Brasil Andrea França, Pontifícia Universidade Católica do Rio de Janeiro, Brasil André Luiz Martins Lemos, Universidade Federal da Bahia, Brasil Antonio Carlos Hohlfeldt, Pontifícia Universidade Católica do Rio Grande do Sul, Brasil

Arthur Ituassu, Pontifícia Universidade Católica do Rio de Janeiro, Brasil Álvaro Larangeira, Universidade Tuiuti do Paraná, Brasil Ângela Freire Prysthon, Universidade Federal de Pernambuco, Brasil César Geraldo Guimarães, Universidade Federal de Minas Gerais, Brasil Cláudio Novaes Pinto Coelho, Faculdade Cásper Líbero, Brasil Daisi Irmgard Vogel, Universidade Federal de Santa Catarina, Brasil Denize Correa Araujo, Universidade Tuiuti do Paraná, Brasil Eduardo Antonio de Jesus, Pontifícia Universidade Católica de Minas Gerais, Brasil

Daniela Zanetti, Universidade Federal do Espirito Santo, Brasil Eduardo Vicente, Universidade de São Paulo, Brasil Elizabeth Moraes Gonçalves, Universidade Metodista de São Paulo, Brasil Erick Felinto de Oliveira, Universidade do Estado do Rio de Janeiro, Brasil Francisco Elinaldo Teixeira, Universidade Estadual de Campinas, Brasil Francisco Paulo Jamil Almeida Marques, Universidade Federal do Paraná, Brasil

Gabriela Reinaldo, Universidade Federal do Ceará, Brasil Goiamérico Felício Carneiro Santos, Universidade Federal de Goiás, Brasil Gustavo Daudt Fischer, Universidade do Vale do Rio dos Sinos, Brasil Herom Vargas, Universidade Municipal de São Caetano do Sul, Brasil Itania Maria Mota Gomes, Universidade Federal da Bahia, Brasil
Janice Caiafa, Universidade Federal do Rio de Janeiro, Brasil Jiani Adriana Bonin, Universidade do Vale do Rio dos Sinos, Brasil José Afonso da Silva Junior, Universidade Federal de Pernambuco, Brasil José Luiz Aidar Prado, Pontifícia Universidade Católica de São Paulo, Brasil Juçara Gorski Brittes, Universidade Federal de Ouro Preto, Brasil Kati Caetano, Universidade Tuiuti do Paraná, Brasil

Lilian Cristina Monteiro França, Universidade Federal de Sergipe, Brasil Liziane Soares Guazina, Universidade de Brasília, Brasil Luíza Mônica Assis da Silva, Universidade de Caxias do Sul, Brasil Luciana Miranda Costa, Universidade Federal do Pará, Brasil Malena Segura Contrera, Universidade Paulista, Brasil Maria Ogécia Drigo, Universidade de Sorocaba, Brasil Maria Ataide Malcher, Universidade Federal do Pará, Brasil Marcia Tondato, Escola Superior de Propaganda e Marketing, Brasil Marcel Vieira Barreto Silva, Universidade Federal da Paraíba, Brasil Maria Clotilde Perez Rodrigues, Universidade de São Paulo, Brasil Maria das Graças Pinto Coelho, Universidade Federal do Rio Grande do Norte, Brasil

Mauricio Ribeiro da Silva, Universidade Paulista, Brasil

Mauro de Souza Ventura, Universidade Estadual Paulista, Brasil Márcio Souza Gonçalves, Universidade do Estado do Rio de Janeiro, Brasil Micael Maiolino Herschmann, Universidade Federal do Rio de Janeiro, Brasil Mirna Feitoza Pereira, Universidade Federal do Amazonas, Brasil Nísia Martins Rosario, Universidade Federal do Rio Grande do Sul, Brasil Potiguara Mendes Silveira Jr, Universidade Federal de Juiz de Fora, Brasil Regiane Regina Ribeiro, Universidade Federal do Paraná, Brasil Rogério Ferraraz, Universidade Anhembi Morumbi, Brasil Rose Melo Rocha, Escola Superior de Propaganda e Marketing, Brasil Rozinaldo Antonio Miani, Universidade Estadual de Londrina, Brasil Sérgio Luiz Gadini, Universidade Estadual de Ponta Grossa, Brasil Simone Maria Andrade Pereira de Sá, Universidade Federal Fluminense, Brasil Veneza Mayora Ronsini, Universidade Federal de Santa Maria, Brasil Walmir Albuquerque Barbosa, Universidade Federal do Amazonas, Brasil

\section{COMISSÃO EDITORIAL}

Cristiane Freitas Gutfreind

Pontifícia Universidade Católica do Rio Grande do Sul, Brasil

Irene Machado

Universidade de São Paulo, Brasil

\section{CONSULTORES AD HOC}

Claudia Peixoto de Moura, Pontificia Universidade Católica do Rio Grande do Sul, Brasil Francisco Rüdiger, Pontifícia Universidade Católica do Rio Grande do Sul, Brasil Juremir Machado da Silva, Pontifícia Universidade Católica do Rio Grande do Sul, Brasil Maria Aparecida Baccega, Universidade de São Paulo, Brasil

Roberto Tietzmann, Pontifícia Universidade Católica do Rio Grande do Sul, Brasil

\section{EQUIPE TÉCNICA}

ASSISTENTE EDITORIAL I Márcio Zanetti Negrini

REVISÃO DE TEXTOS I Press Revisão

EDITORAÇÃO ELETRÔNICA I Roka Estúdio

CONTATO I revistaecompos@gmail.com
COMPÓS I www.compos.org.br

Associação Nacional dos Programas de Pós-Graduação em Comunicação

Presidente

Edson Fernando Dalmonte

Programa de Pós-Graduação em Comunicação

e Cultura Contemporânea - UFBA

edsondalmonte@uol.com.br

Vice-presidente

Cristiane Freitas Gutfreind

Programa de Pós-Graduação em Comunicação Social - PUC-RS cristianefreitas@pucrs.br

Secretário-Geral

Rogério Ferraraz

Programa de Pós-Graduação em Comunicação

Universidade Anhembi Morumbi

rogerioferraraz@anhembimorumbi.edu.br 